\title{
História, Reino de Deus e Socialismo: numa breve abordagem a Paul Tillich
}

\author{
Victor Siqueira Santos*
}

\section{RESUMO}

$\mathrm{O}$ artigo tem como objetivo mostrar a relação entre história, Reino de Deus e Socialismo no pensamento do teólogo e filósofo teuto-americano Paul Tillich (1886-1965). Para isso, exporemos, primeiramente, as ideias do autor acerca do conceito de história e sua relação com o símbolo cristão do Reino de Deus, conforme desenvolvida em sua teologia sistemática. Posteriormente, mencionaremos a situação da Alemanha no período pós-Primeira Guerra, destacando o crescimento do socialismo religioso alemão, do qual Tillich fez parte. Deste movimento, enfatizaremos a articulação política entre história e Reino de Deus, sobretudo através do conceito de kairós. Por fim, tentaremos expor o método teológico que fundamenta a teologia de Paul Tillich e do socialismo religioso, possibilitando esta forma particular de articulação.

Palavras-chave: história; Reino de Deus; socialismo; kairós; Paul Tillich.

\section{HISTORY, KINGDOM OF GOD AND SOCIALISM: A BRIEF AP- PROACH TO PAUL TILLICH}

\begin{abstract}
This article aims to expose the relation between history, Kingdom of God and socialism in Paul Tillich's thought (1886-1965). In order to achieve it, it will be first exposed the author's ideas on the concept of history and its relation with the Christian symbol Kingdom of God as developed in his Systematic Theology. After that the paper will mention the post-First-War Germany situation, highlighting the rising part of Tillich's religious socialism. About this movement, the political articulation between history and Kingdom of God is emphasized, mainly through the concept

* Mestre (2017) e Doutorando em teologia sistemático-pastoral no PPG em teologia da Pontifícia Universidade do Rio de Janeiro, PUC-Rio. E-mail: sem.victorsantos@gmail. com. Lattes: http://lattes.cnpq.br/7051636480812647.
\end{abstract}


of Kairos. At last, the ground method for Paul Tillich's and religious socialism's theology is presented as it makes possible this particular way of articulation.

Keywords: history; Kingdom of God; socialism; kairos; Paul Tillich.

\section{Introdução}

Sendo fiel ao seu próprio método da correlação, Paul Tillich, em sua Teologia Sistemática, correlaciona sempre um tema ligado às questões existenciais humanas a um tema estritamente teológico. Assim ele o faz no Volume 1, no qual correlaciona "a razão e a revelação" e "o ser e Deus"; Volume 2, no qual correlaciona "a existência e o Cristo"; Volume 3, no qual correlaciona "a vida e o Espírito" e "a história e o Reino de Deus". No presente trabalho, nos ocuparemos a abordar, brevemente, a última correlação de sua Teologia Sistemática: “A história e o Reino de Deus", direcionando tal relação para suas implicações no pensamento político de Tillich.

Para realizar tal correlação, Tillich busca, primeiramente, levantar as ideias mais comuns acerca do conceito de "história" a partir do ponto de vista filosófico e historiográfico. A própria busca pelo significado do conceito de "história" levanta perguntas existenciais acerca de suas cosmologias e utopias. Para Tillich, essas perguntas são respondidas através do símbolo cristão do "Reino de Deus". Tomando o Reino de Deus como um símbolo cristão, Tillich busca superar o dualismo que se construiu tradicionalmente entre o caráter imanente e o caráter transcendente do Reino. Ele o faz, principalmente, trazendo como exemplos dessa superação o "profetismo bíblico" e a própria manifestação do Reino em Jesus Cristo.

Esta visão teológica tillichiana será fundamental para a construção de sua visão política como participante do socialismo religioso alemão. Sendo participante ativo deste movimento, Tillich foi um grande articulador entre as elaborações teológicas da igreja luterana prussiana e o movimento socialista. Dentre tais articulações, o conceito de Reino de Deus trazido por Tillich certamente está entre os principais, pois, nele, o autor afirma que nas ações humanas, inclusive no socialismo, o Reino de Deus é antecipado, ainda que fragmentariamente. 


\section{História e Reino de Deus}

Paul Tillich, ao abordar o tema da "história", procura verificar as hermenêuticas sobre tal conceito que mais exercem influência sobre seu tempo. Ele assim o faz buscando uma abordagem filosófica e antropológica, como já lhe é característico. Os passos concretos dados por Tillich são: primeiramente, buscar refletir sobre o que é a história para o ser humano; depois, destacar algumas interpretações sobre história que ele tem por inadequadas; e, por fim, discorrer acerca da interpretação de história que ele tem por adequada.

Resgatando a semântica da palavra "história", Tillich detecta que a história, antes de ser os fatos acontecidos em si, é a concepção desses fatos. Deste modo, distingue-se a consciência histórica dos acontecimentos históricos, sendo a primeira sempre um olhar lançado sobre o segundo. O autor diz:

A palavra grega história significa primordialmente pesquisa, informação, relato. Só secundariamente ela se refere aos eventos pesquisados e relatados. Fica claro que, para aqueles que usaram originalmente a palavra "história", o aspecto subjetivo precedia o objetivo. A consciência histórica, segunda esta visão, "precede" os acontecimentos históricos. (TILLICH, 2014, p. 238)

Sendo assim, é natural que os relatos históricos, quando transmitidos ao longo de uma tradição, tragam consigo símbolos que, unidos ao relato histórico, auxiliam o grupo na recepção e na concepção da realidade histórica. A ideia de "história" como uma dissecação das interpretações a fim de chegar aos fatos nus e crus (conceito que Tillich pensa ser altamente questionável) só se desenvolve ao longo da modernidade ocidental. (TILLICH, 2014, p. 738) E, para o autor, mesmo esta historiografia moderna está inevitavelmente envolvida com interpretações simbólicas da realidade. Tillich diz:

Ninguém escreve história a partir de um "lugar acima de todos os lugares". Esta reivindicação não seria menos utópica do que a reivindicação de que estamos nos aproximando de condições sociais ideais. Toda historiografia depende tanto de ocorrências reais quanto de sua recepção por parte de uma consciência histórica concreta. Não existe história sem ocorrências factuais, e não existe história sem a recepção e interpretação das ocorrências factuais pela consciência histórica. (TILLICH, 2014, p. 739) 
Com isso, Tillich quer dizer que mesmo a pesquisa histórica mais rigorosamente acadêmica possui uma interpretação da história. Esta dualidade entre o caráter objetivo e subjetivo da interpretação histórica faz com que o próprio olhar de um grupo ou de uma pessoa sobre a história ganhe um caminho próprio no qual se envolvem visões características filosóficas, sociais e políticas da realidade. A esse fenômeno Tillich chama de interpretações históricas. Com interpretações históricas, ele não está falando de interpretações de fatos específicos, mas das visões históricas que estão por trás de tais interpretações, condicionando-as e direcionando-as. (TILLICH, 2014, p. 782) Nesse sentido, as preocupações tillichianas são: "que tipo de atividade histórica fornece a chave correta de interpretação? Ou, em outras palavras, de que grupo histórico se deve participar para obter a visão universal que abre o sentido da história? (...) que grupo e consciência vocacional são capazes de fornecer uma chave para a história como um todo?" (TILLICH, 2014, p. 783). A partir dessas perguntas, Tillich analisará cinco interpretações da história às quais ele considera inadequadas, para, ao final, apresentar uma proposta que, em sua visão, é a resposta adequada para o sentido da história. As interpretações rejeitadas por Tillich são: 1- Interpretação trágica; 2- Interpretação mística; 3- Interpretação mecanicista; 4- Interpretação utópica; 5- Interpretação transcendental. ${ }^{1}$

\section{Respostas inadequadas para o sentido da história}

\subsubsection{Interpretações não-históricas}

As três primeiras interpretações da história elencadas por Tillich são, segundo ele, tipos não-históricos de tal exercício interpretativo, ou, também segundo o autor, são respostas negativas à pergunta acerca do sentido histórico. Para tais tipos de interpretação, a história não possui um alvo específico, um fim que ela atingirá seja dentro da história ou

\footnotetext{
As três primeiras interpretações, Tillich classifica como tipos não-históricos pelo fato de elas interpretarem a história como um fim em si mesma, sem que esta tenha um alvo intra-histórico ou para além da história (interpretação trágica; interpretação mística; interpretação mecanicista). As duas últimas interpretações, ele reconhece como históricas, mas, mesmo assim, as julga inadequadas (interpretação utópica; interpretação transcendental) por motivos que serão expostos mais adiante neste artigo. (Cf. TILLICH, Teologia sistemática, pp. 784-790.)
} 
mesmo para além dela. Ou seja, a história não está caminhando rumo $a$ um cenário específico, seja de forma intra, seja de forma extra ou trans-histórica. Nas palavras de Tillich, os tipos não-históricos de interpretação da história veem esta como “o 'lugar' em que seres individuais vivem suas vidas sem consciência de um telos eterno de suas vidas pessoais." (TILLICH, 2014, p. 784)

Tillich classifica a primeira interpretação não-histórica como a interpretação trágica da história. Esta interpretação está classicamente representada pela visão grega da história. Nela, há um movimento cíclico da história, no qual está envolvido um começo, um fim e um retorno ao ponto inicial. A nível pessoal, o ser humano experimenta, dentro da história sua gênese, auge e queda, "cada um a seu tempo e com limites definidos; não há nada além ou acima deste intervalo de tempo, que é, ele próprio, determinado pelo destino." (TILLICH, 2014, p. 784) Ou seja, o ser humano está preso a um destino que, obrigatoriamente, acontecerá dentro de sua rota de vida que passa por uma gênese, um auge e uma queda, sem que haja nada neste mundo ou num outro, nesta vida ou numa outra, que o livre deste destino. No que tange o cósmico, trata-se de um círculo histórico que possui períodos que se iniciam em um nível de perfeição, mas que vai se deteriorando até que a existência trágica desfigure totalmente a essência daquilo criado. Por isso, a tragédia pressupõe a valorização daquilo que é finito e efêmero. "Exalta-se a glória da vida na natureza, nas nações e nas pessoas, e é exatamente por esse motivo que se deploram sua brevidade, miséria e tragédia. Mas não há qualquer esperança, qualquer expectativa de uma realização imanente ou transcendente da história. Esta visão é não-histórica, e o círculo trágico de nascimento e morte é sua última palavra" (TILLICH, 2014, p. 785).

Outra interpretação da história considerada por Tillich como não-histórica é a interpretação mística. Tillich chama de mística a interpretação histórica que não vê sentido na existência histórica, buscando sempre transcendê-la apesar de não poder evitá-la. O mundo existe e é impossível escapar totalmente dele, por isso, então, deve-se viver nele de maneira harmoniosa possível. Contudo, nada na existência tem valor transcendental, fazendo com que nada seja mais importante para o ser 
humano neste mundo que a missão de transcendê-lo através da busca da união com o uno. Tillich ressalta que:

Em algumas filosofias hindus existe, como no estoicismo, a concepção de ciclos cósmicos de nascimento e morte e da deterioração da humanidade histórica de um período a outro até o último, aquele em que estamos vivendo. Mas em geral não há, neste tipo de interpretação não-histórica da história, consciência do tempo histórico e de um fim para o qual a história se encaminha. (...) A história não tem um objetivo, seja no tempo, seja na eternidade. Também aqui decorre que as ambiguidades da vida sob todas as dimensões são insuperáveis. Existe uma única forma de lidar com elas: transcendê-las e viver dentro delas como alguém que já retornou ao "uno". Este indivíduo não terá mudado a realidade, mas terá se libertado de seu próprio envolvimento nela. Aqui não há qualquer símbolo análogo ao do Reino de Deus. (TILLICH, 2014, p. 785)

Através da interpretação mística da história não há como enxergar valor transcendental em coisas imanentes. Chega-se a um transcendente apesar de e para além das coisas finitas, ignorando-as e libertando-se delas. Tillich cita como exemplo deste tipo de interpretação o neoplatonismo e o espinosismo, no ocidente, e o hinduísmo vedanta, o taoísmo e o budismo, no oriente. $\mathrm{Na}$ atualidade, muitos estudiosos de mística teriam dificuldades de concordar com o uso desse termo para referir-se a esse tipo de interpretação histórica descrito por Tillich. Muitos estudos da área da mística trazem exemplos de místicos e místicas, tanto orientais quanto ocidentais, que carregaram consigo um grande comprometimento com o que é histórico e existencial, lutando contra injustiças e situações desumanas. Estes testemunhos de vida quebram qualquer pretensão de dualismo entre o transcendente e o imanente, mostrando, inclusive, que as suas lutas travadas na dimensão imanente também pode ser lugar de manifestação do transcendente ${ }^{2}$.

A última interpretação não-histórica da histórica exposta por Tillich é a que ele chama de interpretação mecanicista. Ela é fruto da

2 Nomes como Dalai Lama, no Oriente, Etty Hillesum, Thomas Merton e Dom Oscar Romero, no Ocidente, entre outros e outras, são exemplos de quando a experiência mística faz o transcendente se manifestar em ações humanísticas, políticas e ambientais. Para uma visão mais ampla sobre o tema cf. VAZ, H. C. Experiência mística e filosofia na tradição ocidental. São Paulo: Loyola, 2000; BINGEMER, M. C. O mistério e o mundo: paixão por Deus em tempos de descrença. Rio de Janeiro: Rocco, 2013. 
modernidade e seu avanço científico que transforma os fenômenos em dados e enxerga cada vez menos os acontecimentos como parte de um todo histórico e existencial a ser interpretado, mas apenas como mais um fato causado por um outro fato. Não há espaço para uma busca de compreensão do sentido histórico que, de forma mais ampla, leve em consideração o contexto do tempo presente com toda sua relação com o passado. O que há é uma falta de interesse em relação a como os tempos atuais contribuem para uma leitura da história e de nossa existência humana. Os acontecimentos são reduzidos a meros dados efêmeros.

O mecanicismo não enfatiza o elemento trágico da história, como o fez o naturalismo clássico dos gregos. Como ele está intimamente relacionado com o controle técnico da natureza pela ciência e tecnologia, apresenta, frequentemente, um caráter progressista. Mas o mecanicismo pode enveredar para a direção oposta, para a desvalorização cínica da existência em geral e da história em particular. Visão mecanicista normalmente não compartilha com a visão grega a ênfase na grandeza e na tragédia da existência histórica do ser humano, e menos ainda a interpretação da história como um processo que se movimenta em direção a um objetivo intra-histórico ou trans-histórico. (TILLICH, 2014, p. 786)

Olhando para a descrição da interpretação mecanicista da história dada por Tillich, é possível perceber que ela se encaixa perfeitamente em nossos dias atuais, pois satisfaz a voracidade e superficialidade da modernidade tardia, que pensa em resolver problemas contemporâneos - como os problemas ambientais, da fome, da superpopulação e dos choques culturais, religiosos e de gênero, de forma simplista e irresponsável sem olhar seus contextos históricos e muitos menos os dramas existenciais que há por traz deles. É uma leitura histórica mecanicista para líderes políticos cada vez mais mecanizados e descontextualizados.

Após escrever sobre as três interpretações da história definidas como não-históricas ou como respostas negativas à pergunta pelo sentido da história, Tillich parte para o que chama de interpretações histórica da história ou respostas positivas à pergunta pelo sentido da história. Estas últimas, apesar de receber o adjetivo de positivas, não são consideradas por Tillich como repostas adequadas para a pergunta pelo sentido da história, e veremos mais a diante o porquê. 


\subsubsection{Interpretações históricas}

A primeira interpretação histórica da história, descrita por Tillich, é a "interpretação progressista". Ela se divide em duas. De um lado há a interpretação da história como progresso sem fim; de outro, há uma interpretação da história como utopia realizável. A primeira visão histórica progressista foi a que tomou a ala positivista do século XIX. Nela, se entendia que, através das criações culturais humanas infinitas, a humanidade caminharia para uma evolução histórica que, mesmo não tendo um fim realizável, avançaria sempre rumo à perfeição. A criação humana faz a realidade e ela será cada vez mais perfeita. A própria história rejeitou esta visão. Pois ela foi fortemente abalada pelas catástrofes promovidas pelo ser humano no século XX, cujas consequências foram o fim dos otimismos progressistas, cultural e antropológico. Já, na segunda visão progressista, a "visão utópica", a história caminha rumo a uma meta histórica, a um fim que ocorrerá dentro da história mesma. "O utopismo é um progressismo com um alvo definido: a chegada àquele estágio da história em que se superam as ambiguidades da vida." (TILLICH, 2014, p. 787) Esta visão se manifestou sobretudo nas revoluções da modernidade e nos seus princípios democráticos. Contudo, se esquecendo do caráter ambíguo da liberdade humana, essas interpretações históricas viram seus projetos de poder serem frustrados toda vez que ocorria uma proximidade da plenitude de justiça e igualdade esperadas. Tillich rejeita a interpretação utópica por considerá-la idolátrica, visto que confere incondicionalidade àquilo que é condenado e finito. (TILLICH, 2014, pp. 787-788)

A segunda interpretação histórica da história mencionada por Tillich é a "interpretação transcendental". Nela, se dá o dualismo entre a salvação e a transformação histórica. Ao passo que a interpretação utópica visa alcançar uma plenitude de justiça e paz aqui na terra, a interpretação transcendental da história negará qualquer relação entre a salvação dos indivíduos e suas realidades históricas. Assim, ela ignora a relação entre salvação e criação, já que os acontecimentos do âmbito da criação em nada se relacionam com a salvação de Deus. Inevitavelmente, a concepção de "Reino de Deus" que essa interpretação histórica tem só poderá ser a que entende tal reino como "uma ordem supranatural estática em que os indivíduos entram após a morte" (TILLICH, 
2014, p. 789). Isto leva Tillich, o teólogo da cultura, a concluir que: "O tipo transcendental de interpretação histórica é, pois, inadequado, porque exclui a cultura bem como a natureza dos processos salvíficos da história" (TILLICH, 2014, p. 789).

Após tratar de cinco interpretações históricas diferentes, separando-as entre interpretações não-históricas (1- Interpretação trágica; 2- Interpretação mística; 3- Interpretação mecanicista) e interpretações históricas da história (4- Interpretação utópica; 5- Interpretação transcendental), Tillich recusa-as a todas. Para o teólogo, todas essas interpretações são inadequadas, pois não respondem à pergunta humana pelo sentido da história. Tal resposta somente será encontrada no símbolo cristão do Reino de Deus.

\subsection{Reino de Deus como resposta adequada}

Por, obviamente, não se tratar de um reino de forma literal, Tillich atribui ao Reino de Deus o caráter de símbolo. E, de forma categórica, afirma: “O símbolo 'Reino de Deus', para constituir uma resposta positiva e adequada ao sentido da história, deve ser, ao mesmo tempo, imanente e transcendente. Qualquer interpretação unilateral despoja o símbolo de seu poder." (TILLICH, 2014, p. 792) Ao longo da história das religiões bíblicas percebeu-se momentos de ênfase para um lado ou para o outro na relação imanência-transcendência, como também momentos de perfeito equilíbrio. Para o cristianismo, o ápice deste equilíbrio certamente, se deu no Cristo e sua kénose.

Um importante exemplo de equilíbrio da relação imanência-transcendência no conceito de Reino de Deus foi o profetismo. Nele, o Reino de Deus tinha caráter intra e trans-histórico. Mesmo com o forte caráter político e intra-histórico do profetismo bíblico da história de Israel, o qual se pode perceber através do caráter sempre concreto das promessas de Deus ao povo (Terra, lugar de adoração, vitória sobre os inimigos), não se deve negar seu forte elemento transcendental ao reconhecer que é sempre Javé quem vence o inimigo, e ganha as batalhas com a força de seu poder. Tal equilíbrio já não pode ser visto no período intertestamentário, no qual há uma forte ênfase transcendental, transparentes através dos escritos apocalípticos produzidos neste período. Neles, mesmo a figura do Messias que viria como um ser humano 
comum se torna a figura do Filho do Homem, o Homem celestial que trará o juízo de Deus. (TILLICH, 2014, pp. 792-793)

Em Jesus Cristo, se tem, então, a perfeita afirmação que o Reino de Deus envolve imanência e transcendência.

O Novo Testamento acrescenta um elemento novo a estas visões: o aparecimento intra-histórico de Jesus como o Cristo e a fundação da igreja no meio das ambiguidades da história. Tudo isto mostra que a ênfase na transcendência no símbolo "Reino de Deus" não exclui traços intra-históricos de importância decisiva - assim como o predomínio do elemento imanente não exclui o simbolismo transcendente. (TILLICH, 2014, p. 793)

Por isso, o cristianismo está firmado na manifestação central do Reino de Deus, que ocorre na manifestação de Jesus de Nazaré, o Cristo. Por isso, Jesus é o centro da história. Pela fé, o cristianismo afirma que o evento histórico Jesus de Nazaré é o centro de toda a história. A história amadureceu até que chegasse a seu evento central. E, apesar de tanto a preparação para este centro (Antigo Testamento) como o próprio evento revelatório (Jesus de Nazaré), serem concretos, eles desempenham um papel para além disso, pois se tornam parâmetro de um processo de amadurecimento e revelação que ainda estão ocorrendo aqui e agora. Desta feita, com a palavra "centro" Tillich pretende negar de forma definitiva qualquer pretensão de atribuir um início ou fim cronológico ao Reino de Deus, apesar dos parâmetros históricos contidos na tradição cristã. Como afirma Tillich:

Início e fim em relação ao centro da história só podem significar início e fim das manifestações do Reino de Deus na história, e a resposta a esta questão é determinada pelo caráter de seu próprio centro. A história como história da revelação e da salvação começa no momento em que o ser humano se conscientiza da questão última de sua condição alienada e de seu destino no sentido de superar esta condição. Esta consciência se expressou em mitos e ritos desde os primeiros registros humanos; mas não é possível assinalar um momento definido ou uma pessoa ou grupo definidos. (TILLICH, 2014, p. 798)

Com este pensamento, Tillich evidencia mais uma vez seu método filosófico e, mais especificamente, ontológico. Não se pode duvidar 
que, através dele, há um esforço bem sucedido de simultaneidade das dimensões transcendentes e imanentes do Reino de Deus.

\section{O Socialismo Religioso e o Reino de Deus}

O cenário da Alemanha pós Primeira Guerra era de crise econômica, alta inflação e uma indústria que formava e mantinha um proletariado vivendo em situações desumanas e condições precárias. Como descreve Tillich:

Haviam (as massas populares) sido transformadas de pessoas em objetos de trabalho que podiam ser comprados. Precisavam vender-se para sobreviver. Viviam em alojamentos em cidades como Berlim ou na região do Ruhr, onde se concentrava a maior parte da indústria, e vi o tipo de existência desumanizada que essa gente suportava. (TILLICH, 2010, p. 170)

Após a assinatura do Tratado de Versalhes, que determinou oficialmente, dentre outras coisas, que a Alemanha perdesse parte de seu território para nações com quem fazia fronteira, todas as suas colônias sob seu comando e pagasse indenizações a outros países por conta dos prejuízos causados pela guerra, a situação da Alemanha era caótica. Antes da assinatura do Tratado, em 13 de maio de 1919, na Conferência de Paz, a comissão econômica alemã submeteu um relatório que descrevia os efeitos sobre a população alemã, caso o tratado fosse assinado. Após dar alguns números do desenvolvimento da Alemanha das duas últimas gerações, o relatório, traz a seguinte lógica: Com a diminuição da produção alemã, causada pelas condições do Tratado, o país não teria condição de importar uma suficiente quantidade de matéria prima necessária para sua produção, o que afetava as indústrias, e, consequentemente, aumentava a necessidade de importação, processo através do qual a demanda do país não seria suprida. A consequência disso seria fome e desemprego para o povo alemão. No fim do relatório, conclui-se que os que assinassem o Tratado estariam assinando a sentença de morte de milhões de alemães (KEYNES, 2002, pp. 158-159). Pois, então, o tratado foi assinado e as consequências não foram muito diferentes das previstas.

Após a Primeira Guerra a Alemanha passou por uma transformação política e social. A igreja protestante prussiana, que tinha como bispo 
supremo o rei da Prússia, via a autoridade política da nobreza ruir. As igrejas cristãs em geral viam o crescimento de um grupo socialista antirreligioso e isso fez com que a parte mais influente da igreja se posicionasse com distância deste grupo, o que dificultava uma reação sócio-política ou uma teologia social por parte da igreja. Mesmo com a posterior ascensão do nazismo, as igrejas cristãs não se posicionaram em uma luta que resistisse a este poder que, em certa altura, se apresentava quase como uma fé religiosa. (TILLICH, 2000, p. 218) O socialismo religioso foi uma tentativa de superar o abismo que existia entre a ortodoxia das igrejas luteranas tradicionais e o surgimento de um socialismo a-religioso. O movimento político-religioso buscava unir a visão sócio-política à visão teológica.

Dentro da teologia do Socialismo Religioso, a relação entre o símbolo Reino de Deus e o cenário político da Alemanha daquela época era bastante explorada. Pois o movimento "trabalhava a partir de uma compreensão intra-histórica do reino de Deus, sem abandonar a visão de realização transcendental do reino." (TILLICH, 2010, p. 238) Ou seja, a leitura histórica do socialismo religioso estava fundamentada pela afirmação de que o símbolo do Reino de Deus era resposta adequada para a pergunta pelo sentido da história. Ideia trabalhada por Tillich em sua teologia sistemática e que exploramos aqui, há pouco. Esta leitura não permitia que houvesse abismo entre os anseios socialistas de realização histórica e a busca religiosa do Reino de Deus. A fim de superar tal abismo o movimento socialista religioso articulou vários conceitos teológicos, um dos mais importantes deles foi, sem dúvida, o conceito de Kairós.

Em sua definição, Tillich diz que Kairós "é a entrada do eterno na história em virtude da luta contra o poder demônico. Kairós significa tempo, o tempo certo, o tempo qualitativo em contraste com chronos, o tempo do relógio, o tempo quantitativo." (TILLICH, 2010, p. 240) Todas as estruturas sociais e antropológicas possuem simultaneamente potenciais destrutivos e criativos. O termo demônico é usado por Tillich para a descrição dos elementos destrutivos na sociedade e no indivíduo. O demônico é aquilo que aliena uma pessoa ou um grupo, distorcendo seus valores mais profundos. Por outro lado, em contraste com o demônico está o kronos. A irrupção do eterno no temporal. O transcendente 
dentro do imanente, a potencialidade criativa dos grupos e das pessoas. Enquanto o conceito de demônico evidencia a vulnerabilidade do que é finito, o conceito de kairós evidencia transcendentalidade do que é finito, sem se esquecer de suas limitações. Com o conceito de Kairós, o socialismo religioso procurava superar o transcendentalismo das igrejas tradicionais, mostrando que "o eterno pode entrar no temporal e iniciar uma nova era." (TILLICH, 2010, p. 240) Por outro lado, a partir do conceito de Reino de Deus que não é realizado plenamente no tempo, o movimento se livrava dos utopismos que acreditavam na realização de um tempo perfeito e sem traços demônicos.

Para Tillich, através de momentos específicos na história, é possível uma irrupção do eterno, no presente. A história possui uma dinâmica autotranscendente, permitindo que, em um dado momento, ela amadureça "a ponto de poder receber a irrupção da manifestação central do Reino de Deus.” (TILLICH, 2014, p. 800) A noção de kairós, certamente, estreita a separação entre uma noção de Reino de Deus que fosse totalmente transcendente, relacionando o Reino com o então tempo presente. De tal forma que o que ocorria historicamente poderia, escatologicamente, ser sinal do Reino vindouro. Tillich diz que quando surgiu o socialismo religioso, "kairos deveria expressar o sentimento de muitas pessoas na Europa central, após a Primeira Guerra Mundial, de que surgira um momento da história prenhe de uma nova compreensão para o sentido da história e da vida." (TILLICH, 2014, p. 800)

Esta fala do teólogo explicita bem seu método teológico, que está presente no conceito de kairós e em muitos outros. Tillich busca sempre a partir de uma situação contextual tirar uma mensagem teológica. $\mathrm{Ou}$ seja, há primeiramente o movimento de olhar para a realidade e ser interpelado por ela, para, posteriormente pensar que dimensão religiosa ela possui e revela. A ordem destes fatores é de suma importância, pois, se este método é aplicado na "contramão", então pensa-se, primeiro, numa dimensão religiosa que nomeia e julga a realidade, e, por consequência, esta realidade não seria nada mais que acontecimentos históricos que, como peças dentro de um quebra-cabeças, emolduram um imaginário religioso já definido. Estas duas formas de se aproximar da realidade é que diferencia o pensamento teológico de Tillich e de seu contemporâneo Karl Barth, por exemplo. 
O Barth que ajudou a desenvolver a teologia dialética também fez parte do socialismo religioso da Suíça, ainda antes de Tillich. "Na sua paróquia de Safenwill, Barth foi levado a ligar-se ao movimento socialista religioso (...), pela necessidade prática de tomar posição a respeito da questão do antagonismo de classes entre industriais e trabalhadores, e de refletir sobre as implicações teológicas de tal prática." (HIGUET, 2017, p. 220) O tom dado a essas implicações teológicas segue o fio condutor do pensamento barthiano, a saber, Deus e sua palavra sempre se colocarão em total oposição ao ser humano e sua história. Em linguagem tillichiana, Barth faz uma teologia querigmática, pois "enfatiza a verdade imutável da mensagem (querigma) contra as exigências cambiantes da situação." (TILLICH, 2014, p. 22) Em outras palavras, Barth enfatiza a transcendência frente à imanência, o extra-histórico frente ao intra-histórico, esses polos, mesmo se relacionando, possuem valores substancialmente diferentes. Este fundamento teológico aplicado à relação entre o socialismo religioso e o Reino de Deus faz com que Barth enfatize a impossibilidade da realização deste Reino na história, e a limitação das conquistas efetivas do movimento socialista frente ao ideal do Reino. Isto faz com que, após a Primeira Guerra, rompa com o socialismo religioso. Nas palavras de Higuet:

Nesta época, Barth se opõe às simples reformas socialistas, porque não questionam a mecânica e a lógica da ordem social e burguesa capitalista estabelecida e não podem eliminar a injustiça social. Barth situa-se assim do lado esquerdo da social-democracia durante e imediatamente após a guerra. Ele gostaria que a social-democracia voltasse a suas origens e reencontrasse o seu objetivo final, o qual deve também mobilizar os cristãos: a sociedade sem classes. Entretanto, a prioridade dada ao Reino de Deus o impede de interessar-se pelos objetivos concretos e os meios da política socialista. De fato, toda realização humana é apenas uma etapa transitória na espera pela vinda da nova sociedade de Deus. Neste momento, Barth abandona suas atividades no sindicato, por falta de interesse pelas questões práticas cotidianas. Sua visão do objetivo final da luta socialista permanece vaga e indeterminada, desprovida de mediações econômicas e políticas. Ele não vai muito além da ideia de fraternidade e solidariedade na terra e debaixo do céu. (HIGUET, 2017, p. 223)

A desmotivação que afetou a Barth, parece não atingir a Tillich, pelo menos não nos anos 20 e nem com a mesma intensidade. Pois, no 
fundamento político-teológico da visão tillichiana está uma visão intra-histórica do Reino de Deus, na qual a história mesma tem a possibilidade de momentos de realização do Reino, momentos de kairós. Esta diferença político-teológica gerou diferenças na visão e participação de ambos os teólogos no socialismo religioso. Etienne Higuet ressalta a diferença entre os teólogos da seguinte forma:

Assim como Barth, Tillich relaciona o compromisso socialista com a espera profética pelo Reino de Deus. Mas, em vez de deduzir as consequências políticas dos símbolos e conceitos bíblicos, analisa, primeiro, as realidades sociais, como a sociedade burguesa, o proletariado e a práxis socialista, para extrair sua dimensão religiosa. (...) O ser humano está em condições desconstruir o Reino de Deus pela sua prática, mas isto só é possível se o Reino de Deus lhe for antes dado por Deus. Contudo, esse dom não consiste numa irrupção do Reino dos céus transcendente, pois é a própria cidade terrestre que será transformada em Reino pela ação transformadora do ser humano. (HIGUET, 2017, p. 228)

O ponto de partida de Tillich é a realidade. É a partir das escolhas humanas que o Reino de Deus pode ser percebido e construído. Não existe um Reino que é totalmente alheio à realidade ou que se sobreponha a ela. Na visão tillichiana de Reino de Deus, o ser humano "encontra o sentido da realidade por vir, pela experiência vivida do incondicionado em toda realidade condicionada e imanente. Logo, a salvação e libertação não designam mais duas ordens de realidade, mas duas dimensões de uma única realidade." (HIGUET, 2017, p. 228)

O que parece é que, mesmo ciente da ambiguidade que constitui o ser humano e todas as suas construções culturais, Tillich não abre mão da participação construtiva do ser humano no Reino de Deus. $\mathrm{O}$ pessimismo antropológico e a possibilidade do demônico não o atingem com a mesma intensidade com que atinge a Barth. Enquanto o teólogo suíço parece querer eliminar as construções humanas para que o Reino de Deus se cumprisse - politicamente falando, Barth queria, por fim, a abolição do Estado (HIGUET, 2017, p. 225), Tillich enxergava a construção do Reino exatamente na construção humana, tomando parte do proletariado e lutando por um socialismo religioso. "Trata-se (...) de compreender a consciência da massa revolucionária como consciência escatológica do Reino de Deus" (HIGUET, 2017, p. 228). Há uma 
identificação entre a luta socialista e o Reino de Deus. Novamente, em comparação com o posicionamento barthiano, Higuet afirma:

Para Barth, Deus se manifesta pela Sua palavra, por meio das Escrituras, e o socialismo é uma implicação ética: o caminho vai de Deus ao socialismo. Em Tillich, Deus se manifesta na imanência, por meio do conteúdo substancial (Gehalt) da cultura, especialmente nos períodos teônomos e pelo Kairós, e o socialismo torna-se veículo do incondicionado. O caminho vai do socialismo a Deus. (HIGUET, 2017, p. 234)

Em, 1937, Tillich participou da Conferência de Oxford, importante encontro do movimento ecumênico. Nela, ele foi presidente de uma comissão que deveria apresentar uma declaração a respeito das relações da igreja, com o comunismo e o socialismo. A ideia de um Reino de Deus intra-histórico parece permear o documento. Nele, dizia-se que, muitas vezes, Deus fala com a igreja muito mais a partir de grupos históricos tidos como inimigos da religião do que com representantes religiosos propriamente ditos. Nas palavras de Tillich:

Relacionamos nossas ideias com os movimentos revolucionários dos séculos dezenove e vinte e, especialmente, com o movimento socialista. Nosso relatório foi aceito quase sem modificações pela assembleia de Oxford. Embora fosse um avanço muito importante, as igrejas não estavam preparadas para entendê-lo. Hoje, se o conselho Nacional de Igrejas ou o Conselho Mundial de Igrejas fizessem declarações desse tipo, serão ouvidos e entendidos e talvez atacado por alguns. Mas naqueles dias, esse tipo de pronunciamento não podia ser plenamente entendido e foi, por isso, quase esquecido. (TILLICH, 2010, pp. 238-239)

Tillich faz essa declaração na primavera de 1963. Nos dias de hoje, uma declaração dessas, se direcionada para os religiosos cristãos, corre o risco de ser, além de pouco compreendida, também fortemente atacada por muitos.

\section{Conclusão}

Seguindo o método teológico de Paul Tillich em sua teologia sistemática, este artigo entrou na discussão de Tillich acerca do conceito de história, para daí expor a correlação que o teólogo faz entre este conceito e o símbolo cristão do Reino de Deus. A partir desta compreensão, 
foi possível notar que tal correlação, por meio do importante conceito de kairós, foi imprescindível para a visão teológica do socialismo religioso na Alemanha, que por estas e outras contribuições, teve Tillich como um dos seus principais teóricos. Nesta visão, o Reino de Deus é um dom que está para além de toda criação cultural humana, mas que, por outro lado, não pode ser construído sem a coparticipação do humano. O Reino se dá, ainda que não plenamente, através das ações, de momentos de kairós na história. E tendo em conta, não somente o contexto vivido por Tillich, mas a história de uma forma geral, o âmbito político é terreno fértil para tais momentos.

\section{Bibliografia}

KEYNES, John. As consequências econômicas da paz. São Paulo: Imprensa Oficial do Estado; Brasília: Editora Universidade de Brasília, 2002.

HIGUET, E. A teologia de Paul Tillich: utopia, esperança e socialismo. São Paulo: Fonte editorial, 2017.

TILLICH, P. Perspectivas da Teologia Protestante nos séculos XIX e XX. São Paulo: ASTE, 2010.

. Teologia da cultura. São Paulo: Fonte Editorial, 2000.

. Teologia Sistemática. São Leopoldo: Sinodal, 2014. 